\title{
Effect of stress on the life span of the yeast Saccharomyces cerevisiae $^{*}$
}

\author{
Agata Święciło $^{1}$, Zdzisława Krawiec ${ }^{1}$, Jarosław Wawryn ${ }^{1}$, Grzegorz Bartosz ${ }^{2}$ and \\ Tomasz Biliński ${ }^{2}$ \\ ${ }^{1}$ Zamość College of Agriculture, Szczebrzeska 102, 22-400 Zamość, Poland, and \\ ${ }^{2}$ Pedagogical University of Rzeszów, T. Rejtana 16, 35-310 Rzeszów, Poland
}

Received: 31 January, 2000; accepted: 13 March, 2000

Key words: heat shock, osmotic stress, oxidative stress, superoxide dismutase, catalase, aging, Saccharomyces cerevisiae

\begin{abstract}
A correlation is known to exist in yeast and other organisms between the cellular resistance to stress and the life span. The aim of this study was to examine whether stress treatment does affect the generative life span of yeast cells. Both heat shock $\left(38^{\circ} \mathrm{C}, 30 \mathrm{~min}\right)$ and osmotic stress $(0.3 \mathrm{M} \mathrm{NaCl}, 1 \mathrm{~h})$ applied cyclically were found to increase the mean and maximum life span of Saccharomyces cerevisiae. Both effects were more pronounced in superoxide dismutase-deficient yeast strains (up to $50 \%$ prolongation of mean life span and up to $30 \%$ prolongation of maximum life span) than in their wild-type counterparts. These data point to the importance of the antioxidant barrier in the stress-induced prolongation of yeast life span.
\end{abstract}

The budding yeast Saccharomyces cerevisiae constitutes an interesting model for studies of cellular aging. In this species unequal cell division makes possible to differentiate mother cells from daughter cells and, in consequence, to determine the number of divisions a yeast cell can undergo. The replicative life span of yeast cells is limited and there are good rea- sons to assume that the mechanisms governing this limitation are common to yeast and metazoan cells (Jazwinski, 1990; 1996).

The aging of yeast was demonstrated to depend on a number of genes. It has been shown that, in model metazoans, the genes connected with longevity are related to enhanced antioxidative defense (Gems, 1999; Jazwin-

\footnotetext{
${ }_{\text {This work was supported by Grant 281/P04/96/11 from the State Committee for Scientific Research }}$ (KBN). The authors are also indebted to the Polish Science Foundation for supplying us with the scientific equipment indispensable for this research.

${ }^{\bowtie}$ Corresponding author: Tomasz Biliński, Department of Biology, Pedagogical University of Rzeszów, T. Rejtana 16, 35-310 Rzeszów, Poland; tel/fax: (48 17) 853 3504, fax: (48 17) 852 2044; e-mail: bilinski@univ.rzeszow.pl
}

Abbreviations: HSE, heat shock element; Hsf, heat shock factors; SOD, superoxidase dismutase; STRE, stress responsible element.. 
ski, 1996; Orr \& Sohal, 1994). It seems therefore plausible that also in the yeast some genetic determinants of longevity are strictly connected with the antioxidant status of the cell.

Previously we have shown that deficiencies in superoxide dismutases (Wawryn et al., 1999) result in an almost threefold shortening of the life span of individual yeast cells. These mutant cells are known to be hypersensitive to various types of oxidative stress (Biliński et al., 1985; VanLoon et al., 1986). The deficiencies in these enzymes, constituting the first line of defense against oxidative stress, lead to increased levels of reactive oxygen species which result in intracellular damage or even in cell death.

Cells respond to various mild, but potentially dangerous, external factors by developing resistance which extends also to more severe treatments. For example, in yeast a rapid rise of temperature from $22^{\circ} \mathrm{C}$ to $37^{\circ} \mathrm{C}$ results in development of tolerance of $30 \mathrm{~min}$ exposition to $48^{\circ} \mathrm{C}$, at which the untreated cells are killed. Acquirement of resistance is a consequence of synthesis of various sets of proteins whose presence makes possible survival when stressing factors reach the lethal level. During heat shock, expression of many yeast genes depends on activation of heat shock factor (Hsf1), which is bound to heat shock element (HSE) of the promoters of numerous stress inducible genes. The promoters of other genes responding to numerous stress inducing factors, like high osmolarity, starvation or oxidants, possess stress response elements (STRE) (Wieser et al., 1991) sequences, different from HSE (Martinez-Pastor et al., 1996). It seems likely that the list of promoter sequences and transcription factors connected with response to stress is incomplete (Seymour \& Piper, 1999). Interestingly, to the factors which induce the response to stress belong also reactive oxygen species, like hydrogen peroxide, and superoxide generating chemicals (menadione and paraquat) (Lee et al., 1995).
In yeast, the number of genes whose expression is induced after various stress treatments is not identical and their spectrum depends on the type of the stressing factor. As a consequence, although the cells acquire resistance principally to the stressing factor to which they were exposed, they become also partly resistant to other stressing factors. Heat shock increases tolerance of most types of stress. Some of the genes induced by heat shock are involved in protection of cells against oxidative stress. This is understandable because oxygen is involved in heat induced killing of yeast cells (Davidson et al., 1996). It has been reported that genes coding for three antioxidant proteins: catalase $\mathrm{T}$ (Wieser et al., 1991), mitochondrial superoxide dismutase (MnSOD) (Costa et al., 1993) and thioredoxin peroxidase (Lee \& Park, 1998) are induced by heat shock. At least two of them, catalase T (Wieser et al., 1991) and MnSOD (Flattery-O'Brien et al., 1997) possess the STRE sequence in their promoters. The protective role of these proteins under stress conditions has been documented (Costa et al., 1993; Lee \& Park, 1998), although the role of catalases is less evident except in the case of hydrogen peroxide treatment (Biliński et al., 1985; Wieser et al., 1991).

Thus, apparently not only oxidative stress but also the other two types of stress could influence the life span of yeast cells, especially of those whose life span is shortened as a consequence of deficiencies in various antioxidant mechanisms. In fact, a correlation between stress resistance and replicative life span of various yeast strains has been observed (Kennedy et al., 1995). A similar correlation was also found between resistance of skin fibroblasts to oxidative, chemical and alkaline stress and life span of eight mammalian species (Kapahi et al., 1999).

The aim of the present study was to examine whether a relationship does also exist, i.e. whether exposure of yeast mutants deficient in antioxidant enzymes and wild-type yeast to thermal and osmotic stresses affects their life 
span. While this study was in progress, results demonstrating that heat shock applied during the early divisions of $S$. cerevisiae cells increases their life span, have been published (Shama et al., 1998a, b). However, the present study deals with several further questions concerning this problem, viz. (i) the effect of different procedure of shock treatment (cyclically repeated shock) on the replicative life span of S. cerevisiae, (ii) comparison of the effects of heat shock and osmotic stress, and (iii) comparison of the effect of stress on wild-type yeast strains and on yeast mutants deficient in superoxide dismutase.

\section{MATERIALS AND METHODS}

Yeast strains. The following yeast strains were used: wild-type SP-4 (MAT $\alpha$ leu1 arg4) (Biliński et al., 1978), strain DSCD1-1C devoid of CuZnSOD (strain MATa leu1 arg4 sod1) isogenic to SP-4 (Biliński et al., 1985), strain devoid of MnSOD, MnSOD- (MAT $\alpha$ leu2-3,112, his3-11,15 ura3-251,372,328 lac2, sod2\# LEU) and its isogenic parent strain DL 1 (MAT $\alpha$ leu2-3,112, his3-11,15 ura3-251, 372,328 lac2) (VanLoon et al., 1986), both obtained from Dr. G. Schatz (Biozentrum, Basel), a segregant DSCD6-6B (MAT $\alpha$ ura3 $\operatorname{sod} 1$ sod2) deficient in both superoxide dismutases obtained from the cross between MnSOD- and a strain isogenic to DSCD1-1C, bearing sod1 mutation, and DSCD6-6BR (MAT $\alpha$ ura3 SOD1 sod2), a revertant of the former strain deficient only in MnSOD.

Media and growth conditions. Yeast were grown in a standard liquid YPGlucose medium (1\% Difco Yeast Extract, 1\% Yeast Bacto-Peptone, $2 \%$ glucose) on a rotary shaker for about $20 \mathrm{~h}$ at $28^{\circ} \mathrm{C}$ until the logarithmic phase was attained $\left(1-5 \times 10^{7}\right.$ cells $\left./ \mathrm{ml}\right)$, and were then transferred to a solid medium containing $2 \%$ agar (Difco).

The replicative life span was determined according to Kim et al. (1999) on cells placed on agar plates. Briefly, a fresh bud was iso- lated by a micromanipulator and formation of successive buds by such a virgin cell was monitored, each appearing bud being removed using a Narishige MO-202 hydraulic micromanipulator. The number of buds formed by each cell was referred to as its generative life span (Fig. 1). At variance with the original protocol, the plates were not placed overnight in a refrigerator, to avoid the stress caused by cooling and warming.

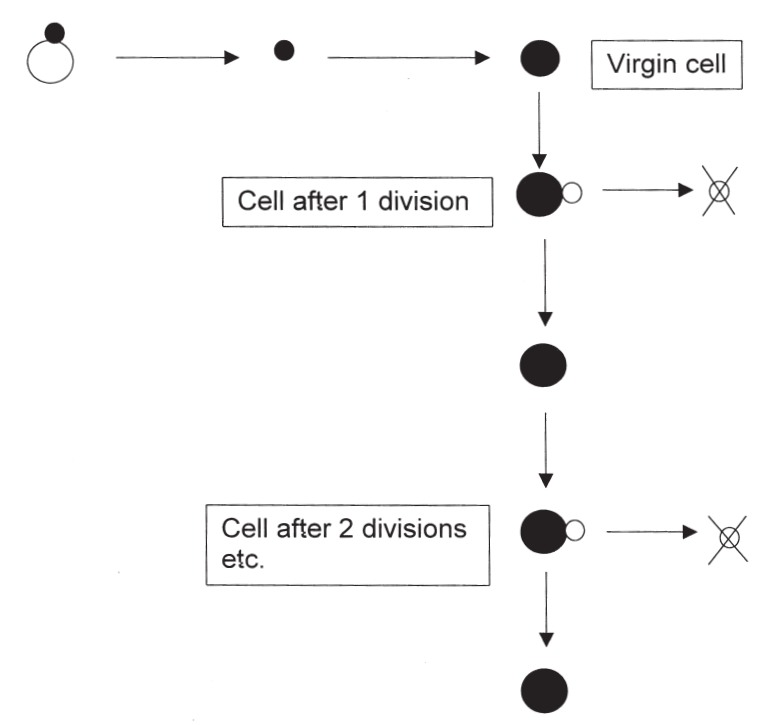

Figure 1. Scheme of the procedure for determination of generative life span of individual yeast cells.

A bud is separated and after maturation constitutes a virgin cell. Divisions of this cell are recorded, descendant buds being removed and discarded. Maximal number of divisions is the generative life span of the yeast cell.

Treatment of cells in liquid medium. Samples of logarithmic cultures of yeast cells in liquid media were subjected to three types of stress: heat, osmotic shock or ethanol. The cells were heat-stressed by a rapid temperature shift from $22^{\circ} \mathrm{C}$ to $38^{\circ} \mathrm{C}$ for $30 \mathrm{~min}$ in a water bath. After $3 \mathrm{~h}$ of subsequent cultivation at $22^{\circ} \mathrm{C}$ the samples were divided into two parts, one of which was subjected to a second heat shock. The procedure was repeated after another $3 \mathrm{~h}$ of cultivation. Osmotic stress was induced by addition of $\mathrm{NaCl}$ solution to a final 
concentration of $0.3 \mathrm{M}$ at which the cells were maintained for $1 \mathrm{~h}$. Alternatively, the cells were treated with $8 \%$ ethanol and incubated for $1 \mathrm{~h}$. After the stress treatment, the cell cultures were centrifuged, the cells were suspended in $50 \mathrm{mM}$ phosphate buffer, $\mathrm{pH}$ 6.8, containing appropriate concentrations of menadione, and incubated for $1 \mathrm{~h}$ at $22^{\circ} \mathrm{C}$. Then the cell suspensions were diluted with the same buffer to a density of $10^{3} / \mathrm{ml}$, plated on agar and their survival was determined by colony counting. The sensitivity of the yeast to oxygen was determined after exposure of 100 $\mu \mathrm{l}$ of yeast suspension $\left(10^{3}\right.$ cells $/ \mathrm{ml}$ ) on Petri dishes to $100 \%$ oxygen for 1 or $2 \mathrm{~h}$. Then the cells were kept for 2 days under the atmosphere of air and the number of colonies formed by the surviving cells was counted. Catalase activity was estimated spectrophotometrically (Beers \& Sizer, 1952) and referred to the cell density estimated by measurement of turbidity of yeast cultures at $700 \mathrm{~nm}$.

Treatment of cells on solid medium. Control and stressed cells were analyzed strictly in parallel. Initial cultures were divided into two groups of virgin cells randomly selected from the same plate. Heat shock was applied by heating one half of Petri dishes in a water bath at $37^{\circ} \mathrm{C}$ for $30 \mathrm{~min}$; then the temperature was lowered to $23^{\circ} \mathrm{C}$. The control Petri dishes were kept throughout at $23^{\circ} \mathrm{C}$. The heating was repeated after a time corresponding to about two generations, i.e. every $3 \mathrm{~h}$ for the wild- type strains (SP-4 and DL 1) and every 5 $\mathrm{h}$ for the remaining strains.

Osmotic stress was performed cyclically at a constant temperature of $28^{\circ} \mathrm{C}$, by transfering single cells to the medium supplemented with $0.3 \mathrm{M} \mathrm{NaCl}$. After $60 \mathrm{~min}$ of incubation the cells were transferred to the standard medium for two generations ( $3 \mathrm{~h}$ and $5 \mathrm{~h}$, respectively), and the stress treatment was repeated. Control cells were grown permanently on the standard medium.

Statistics. Unless stated otherwise, the data presented are means \pm confidence intervals from at least three independent experiments, each comprising measurements of at least 20 cells, unless stated otherwise. Confidence intervals were calculated assuming the Student's distribution of data for $P=0.05$. Statistical significance of differences was estimated using the Students' $t$-test after assessment of the lack of significance of variances with the Snedecore's „F“ test.

\section{RESULTS AND DISCUSSION}

Heat, ethanol and hyperosmotic medium were chosen in this study as stressing factors. Since the CuZnSOD-deficient strain DSCD1$1 \mathrm{C}$ shows a significantly higher sensitivity to superoxide-generating agents, than the other strains tested, it was chosen for studying the protective effects of stress treatment with respect to subsequent exposure to increased intracellular superoxide flux. The results shown in Fig. 2 indicate that, in liquid medium, all types of the applied stress treatment increased significantly the resistance of yeast to pure oxygen and menadione, a superoxidegenerating redox cycling compound. Heat shock was most effective, and since the effects of ethanol stress were similar to those of osmotic stress (Meaden et al., 1999), ethanol stress was excluded from further experiments.

Catalase $\mathrm{T}$ is a protein which is synthesized under the control of the STRE promoter (Wieser et al., 1991), therefore it was chosen as a marker of the response to stress. Both heat shock and osmotic stress augmented catalase $\mathrm{T}$ activity of yeast cells, the effect of osmotic stress being stronger (Fig. 3). It is noteworthy that the elevation of catalase activity was transient and repeated heat shocks were necessary to maintain the increased enzyme level.

Enhancement by heat and osmotic stress of the ability of yeast to cope with oxidative stress prompted us to examine the effect of stress on the life span of yeast. We investigated several strains deficient in superoxide 
dismutases (SOD) as well as their standard counterparts of basically identical genetic background. We expected that the most pronounced differences would be observed in the SOD-deficient cells, in which the levels of antioxidant enzymes (other than SOD) and repair systems are consistently higher than in those cells which divide under non-stressing condi-

A

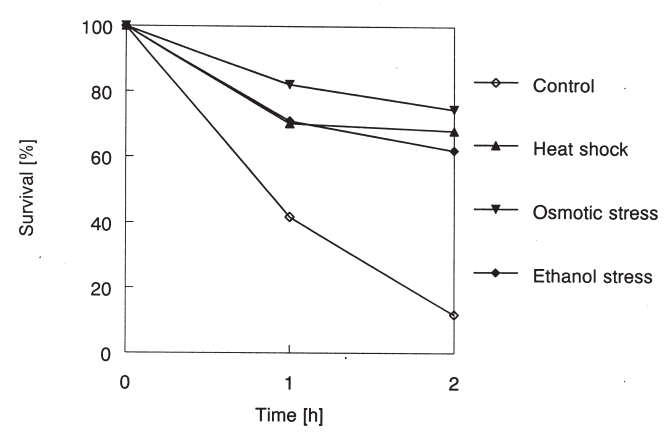

B

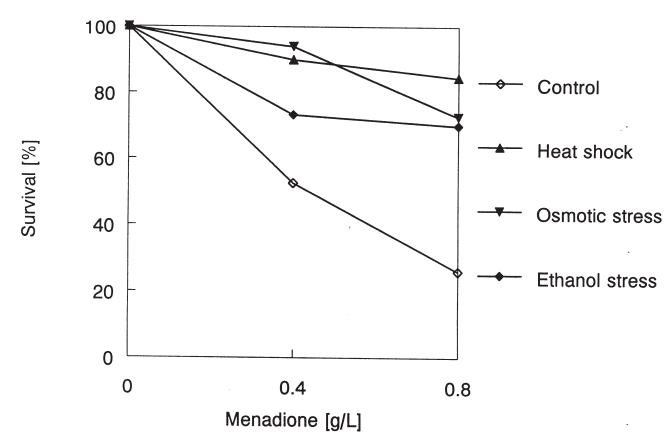

Figure 2. Effect of heat shock, osmotic stress and ethanol stress on the survival of DSCD1-1C strain (devoid of CuZnSOD) in the atmosphere of $100 \%$ oxygen (A) and in the presence of menadione (B).

Cells were subjected to stress in liquid medium, then exposed to oxygen or treated with menadione as described under Materials and Methods. The survival was determined by colony forming on agar plates. Data from a representative experiment are shown.

tions. Taking into account that antioxidative capacity of cells acquired after stress treatment drops down during subsequent cell divisions under non-stressing conditions we assumed that it will be necessary to repeat several times the exposure of cells to stress to keep the protective mechanisms at the highest level during the life span of a cell. Therefore, the experimental procedures differed slightly from those used in our previous experiments and in the experiments of other authors (Shama et al., 1998a, b).

The life span of all the six strains studied was prolonged by heat treatment (Fig. 4). A similar though less pronounced effect was observed after osmotic stress (Fig. 5). The ef-
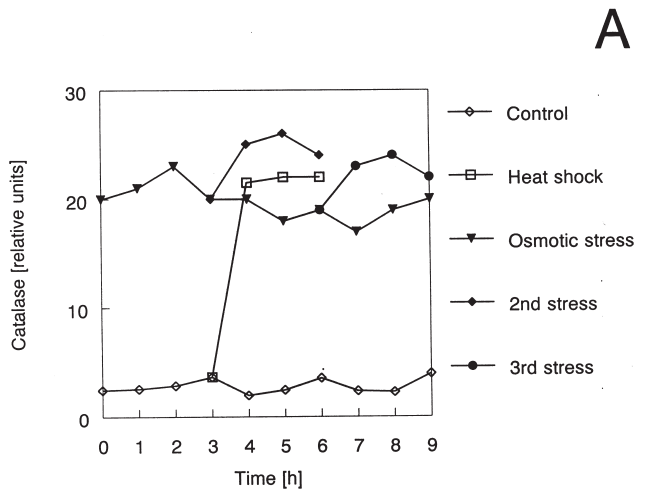

B

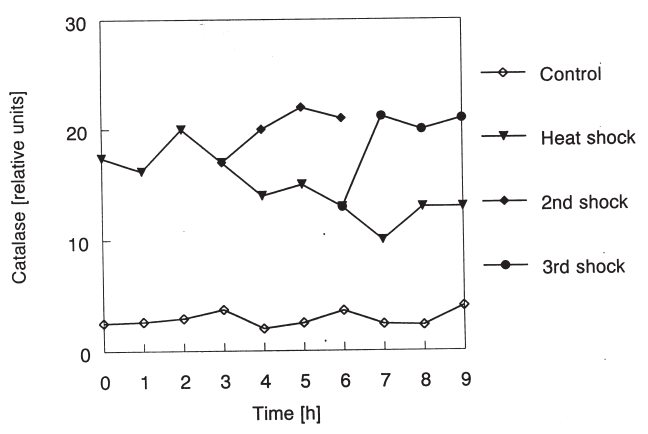

Figure 3. Effect of heat shock and single or repeated osmotic stress (A) and of single and repeated heat shock (B) on the catalase activity of DSCD1-1C strain (devoid of CuZnSOD).

Cells were subjected to stress in a liquid medium and catalase activity was estimated immediately after the stress treatment. Data from a representative experiment are shown.

fects were, as expected, stronger for the SOD-deficient than for the wild-type strains; the mean life span of the DL 1 strain was not prolonged by heat shock although the maximal life span was somewhat extended (Fig. 4). The opposite was true for the effect of osmotic stress on the life span of SP-4 strain (Fig. 5).

The effect of stress on yeast survival is well visible on differential plots in which mean val- 

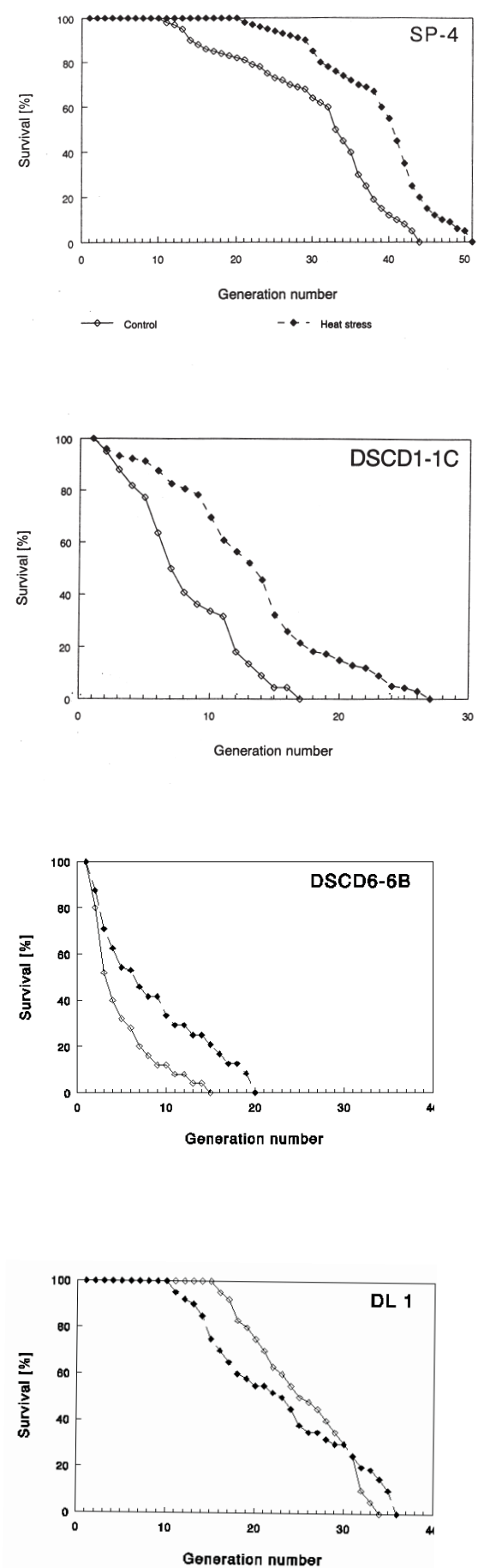

Figure 4. Effect of heat shock on the life span of various yeast strains.

Empty symbols, control cells; filled in symbols, heat-shocked cells. Cells were subjected to the shock treatment $\left(37^{\circ} \mathrm{C}, 30 \mathrm{~min}\right)$ on the solid medium every 3 or $5 \mathrm{~h}$. Control cells were kept at ambient temperature $\left(23^{\circ} \mathrm{C}\right)$. SP4 and DL 1, wild-type strains; DSCB6-6BR1 and MnSOD-, strains devoid of MnSOD; DSCD1-1C, strain devoid of CuZnSOD; DSCD6-6B, strain devoid of CuZnSOD and MnSOD.
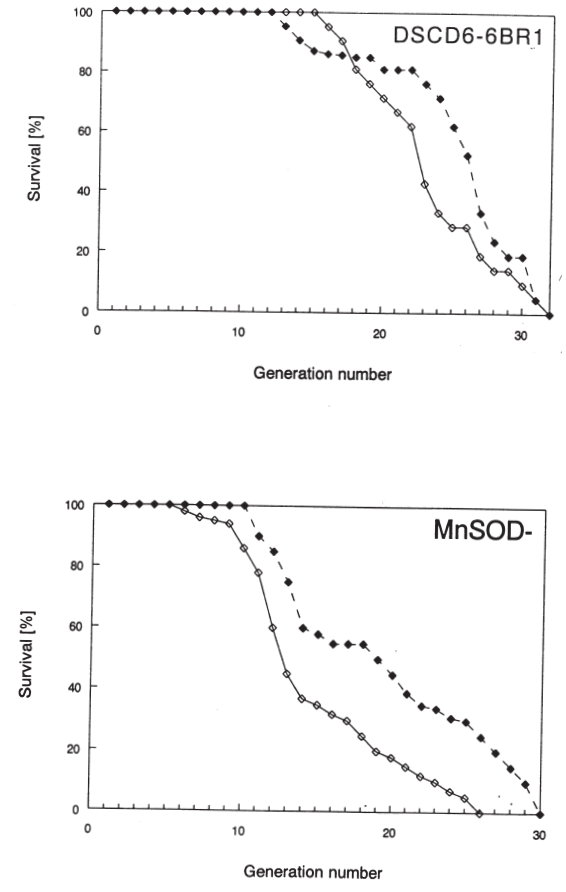

ues of survival of non-stressed cells were subtracted from mean values of survival of the cells subjected to stress treatment (Fig. 6). These plots demonstrate that the effect of stress is especially evident in the late phase of generative life. While the effects of stress treatment are definitely beneficial for SOD-deficient strains, except for the initial negative effect of osmotic stress on the MnSOD- strain (Fig. 6b and d), osmotic stress initially decreases survival of the SP-4 strain (Fig. 6a) while heat shock has mostly a negative effect on the survival of DL 1 strain which turns into a positive one in the very last period of generative life span (Fig. 6c).

The effect of heat shock on the life span of $S$. cerevisiae has been recently reported by Shama et al. (1998a, b). The common conclusion from those and our studies is that heat shock can prolong the life span of yeast cells. However, there are some differences between the results obtained. Shama et al. (1998b) observed beneficial effects of heat shock when applied during the 1st and 4th generations and when the duration of the two heat shocks exceeded $2 \mathrm{~h}$. When 1-h heat shock was applied on a daily basis, a shortening of life span was observed. On the other hand, our experi- 

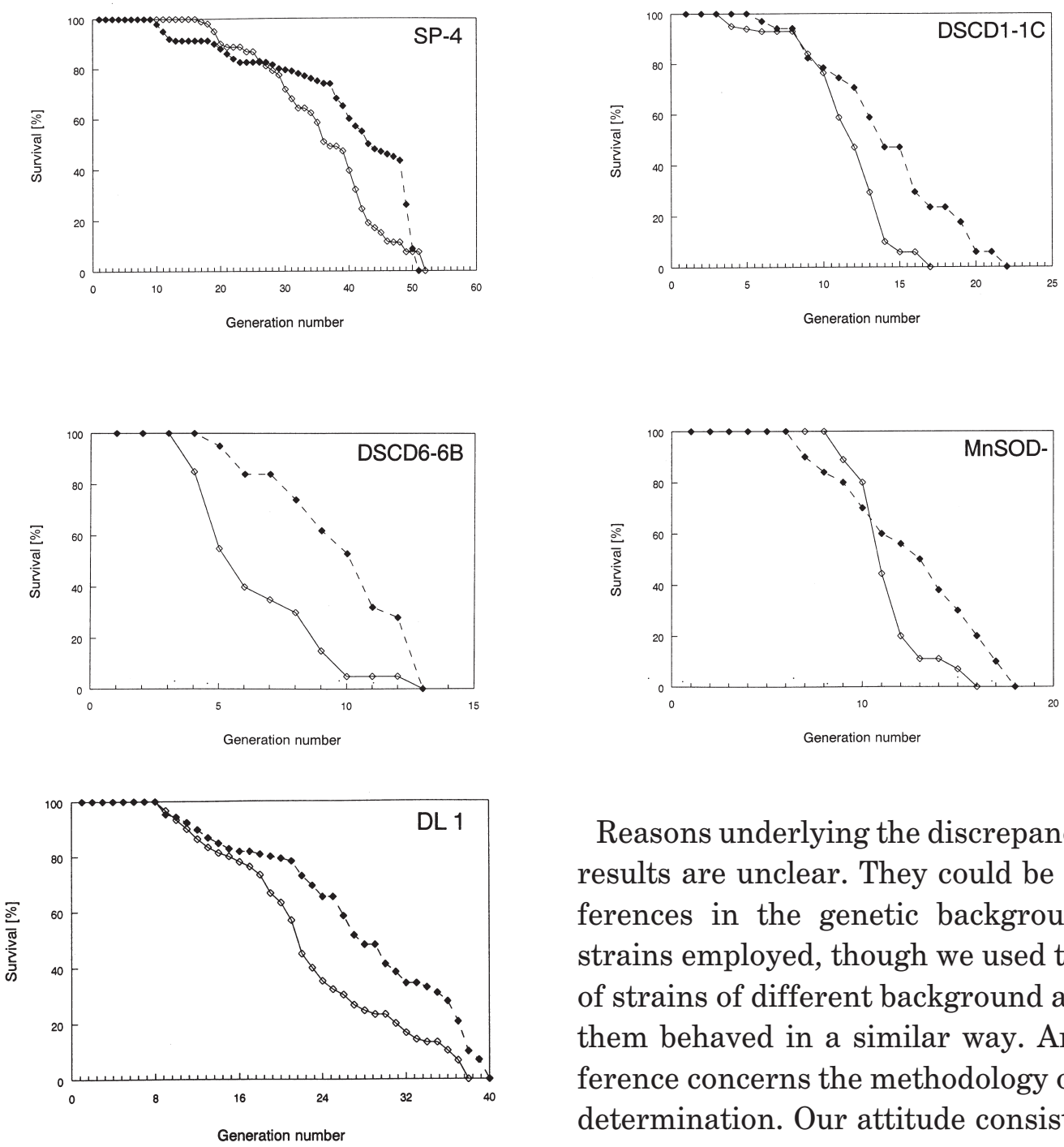

Figure 5. Effect of osmotic stress on the life span of various yeast strains.

Empty symbols, control cells; filled in symbols, osmotically stressed cells. The cells were subjected to stress on solid medium in cycles: stress with $0.3 \mathrm{M} \mathrm{NaCl}$ for $60 \mathrm{~min}$ and then incubation in standard medium for 2 generations. SP4 and DL 1, wild-type strains; MnSOD-, strain devoid of MnSOD; DSCD1-1C, strain devoid of CuZnSOD; DSCD6-6B, strain devoid of CuZnSOD and MnSOD.

mental conditions involved repetition of stresses every two generations throughout the experiment. However, in our hands an experimental protocol similar to that of Shama et al. (1998) (heat shock during the 1st and 4th generations) did not affect significantly the life span of DL 1 and MnSOD-strains (Table 1).

Reasons underlying the discrepancy of these results are unclear. They could be due to differences in the genetic background of the strains employed, though we used two groups of strains of different background and both of them behaved in a similar way. Another difference concerns the methodology of life span determination. Our attitude consisted in constant monitoring of cell divisions, without placing the cells in a refrigerator overnight. We were afraid that such a treatment, though undoubtedly more convenient for an investigator, involves for the cells a stress of temperature change, undesirable especially in experiments on heat shock. Irrespective of the discrepancies, our results confirm that heat shock may prolong the life span of yeast cells and demonstrate that osmotic stress has the same effect.

Obvious candidates for mediation of the beneficial effects of shock on yeast life span are the heat shock proteins. Those proteins may facilitate repair or removal of damaged protein molecules. If the mechanisms of aging include accumulation of malformed macromolecules, prevention of this effect by heat shock 

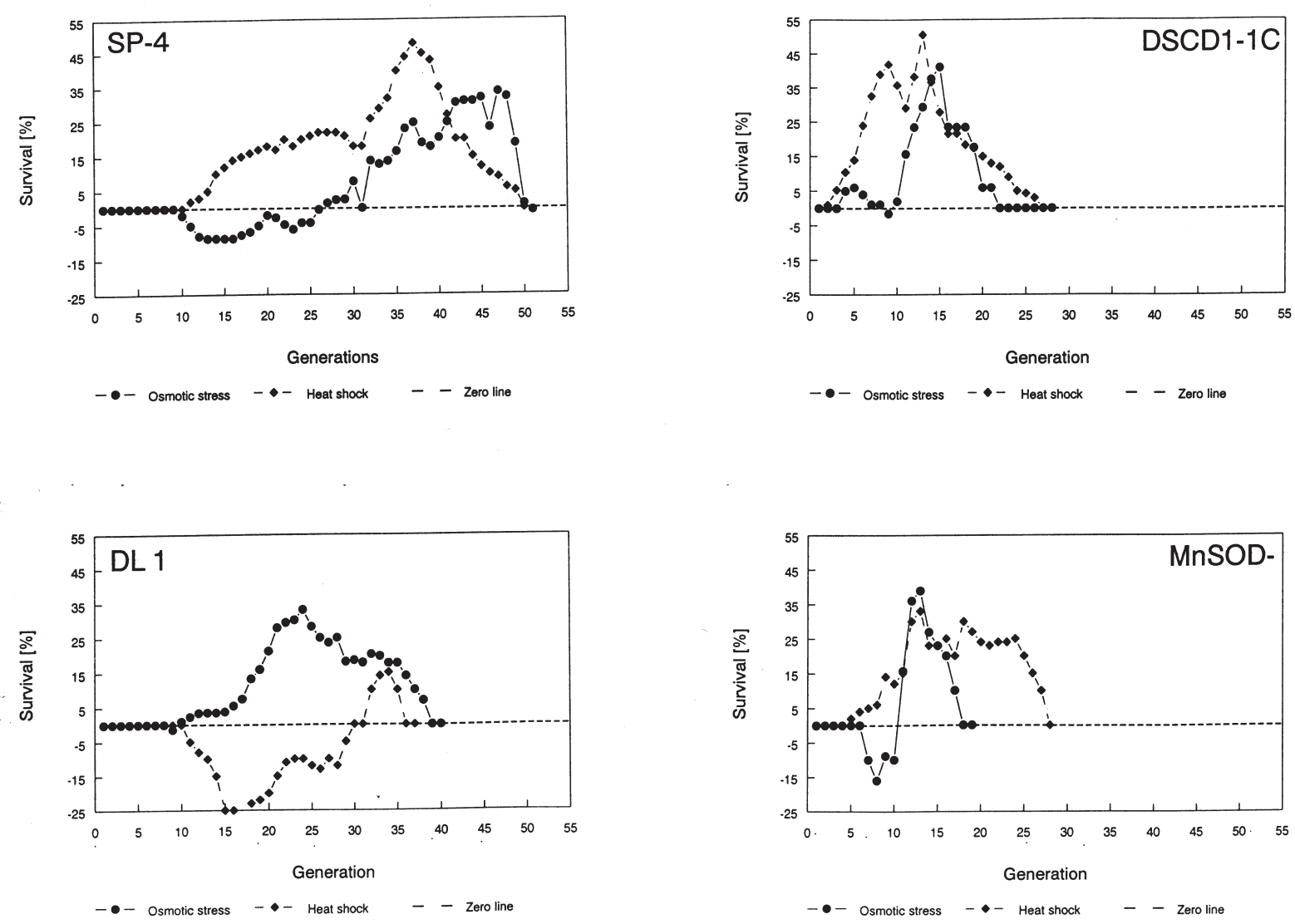

Figure 6. Differential plots showing the effect of stress treatment on the survival of various yeast strains.

Mean values of survival of control cells (not subjected to stress) were subtracted from mean values of survival after stress treatment.

proteins may be of importance. Alternatively, shock treatment may enhance the transcription of longevity-assurance genes. The evi- the antioxidative defense. In fact, deletion of superoxide dismutase (resulting in permanent oxidative stress) and stress treatment

Table 1. Effect of heat shock applied only during the 1st and 4th generations on mean replicative life span, maximal replicative life span, generation time and mean chronological life span of control and MnSOD-deficient strains; $\mathbf{n}=\mathbf{1 1}$

\begin{tabular}{lcccc}
\hline Strain: & $\begin{array}{c}\text { DL 1, } \\
\text { control }\end{array}$ & $\begin{array}{c}\text { DL 1, } \\
\text { heat-shocked }\end{array}$ & $\begin{array}{c}\text { MnSOD- } \\
\text { control }\end{array}$ & $\begin{array}{c}\text { MnSOD- } \\
\text { heat-shocked }\end{array}$ \\
\hline Mean replicative life span & $25.4 \pm 2.3$ & $25.3 \pm 3.1$ & $13.2 \pm 3.5$ & $14.7 \pm 2.6$ \\
Maximal replicative life span & 31 & 32 & 24 & 24 \\
Generation time (min) & $156 \pm 8$ & $154 \pm 6$ & $211 \pm 14$ & $199 \pm 10$ \\
Mean chronological life span (h) & 66.1 & 64.8 & 46.3 & 48.6 \\
\hline
\end{tabular}

dence by other authors suggests the involvement of HSP104, RAS1 and RAS2 in the effect of heat shock on yeast life span (Shama et al., 1998a, b).

The list of proteins induced by stress treatments in the yeast includes also elements of show reciprocal effects on the life span of yeast cells. Reasons for the much stronger beneficial effects of stress treatment on SODdeficient cells as compared with their wildtype counterparts are intriguing. Involvement of antioxidants and/or antioxidative enzymes 
in the life span prolongation appears plausible in view of the evidence that the action of various types of stress is mediated by oxidative stress (Costa et al., 1993; Davidson et al., 1996; Lee \& Park, 1998). The increase in catalase activity is among the obvious effects of stress (Fig. 2) but it seems improbable that induction of catalase contributes to the increased life span of yeast as catalase deficiency was shown not to affect its life span (Wawryn et al., 1999). MnSOD gene is also under the control of the STRE sequence (Flattery-O'Brien et al., 1997) but life span prolongation has been observed also in the MnSOD-deficient strains (Figs. 3 and 4). It cannot be excluded, however, that other elements of the antioxidative defense which bring about increased resistance to oxidative stress contribute to the increased life span of the yeast (Fig. 1). Elevation of glutathione content (Jaruga et al., 1995) and thioredoxin peroxidase activity (Lee \& Park, 1998) were observed in yeast subjected to a single heat shock, although such effects could be strain-dependent (Costa et al., 1993, Jaruga et al., 1995). The question of mechanisms underlying prolongation of life span of the yeast cells (and possibly of other organisms) by stress treatment and the possible role of the antioxidant barrier in this phenomenon undoubtedly deserves further studies.

\section{R E F E R E N C E S}

Beers, R.F. \& Sizer, J.W. (1952) A spectrophotometric method for measuring the breakdown of hydrogen peroxide by catalase. J. Biol. Chem. 195, 133-138.

Biliński, T., Krawiec, Z., Liczmański, A. \& Litwińska, J. (1985) Is hydroxyl radical generated by the Fenton reaction in vivo? Biochem. Biophys. Res. Commun. 130, 533-539.

Biliński, T., Łukaszkiewicz, J. \& Śledziewski, A. (1978) Demonstration of anaerobic catalase synthesis in the cz1 mutant of Saccharomyces cerevisiae. Biochem. Biophys. Res. Commun. 83, 1225-1233.

Costa, V., Reis, E., Quintanilha, A. \& MoradasFereira, P. (1993) Acquisition of ethanol tolerance in Saccharomyces cerevisiae. Key role of mitochondrial superoxide dismutase. Arch. Biochem. Biophys. 300, 608-614.

Davidson, J.F., Whyte, B., Bissinger, P.H. \& Schiestl, R.H. (1996) Oxidative stress is involved in heat-induced cell death in Saccharomyces cerevisiae. Proc. Natl. Acad. Sci. U.S.A. 93, 5116-5121.

Flattery-O’Brien, J.A., Grant, C.M. \& Dawes, I.W. (1997) Stationary-phase regulation of the Saccharomyces cerevisiae SOD2 gene is dependent on additive effects of HAP2/3/4/5and STRE-binding elements. Mol. Microbiol. 23, 303-312.

Gems, D. (1999) Nematode ageing: Putting metabolic theories to the test. Curr. Biol. 9, R614-R616.

Jaruga, E., Lapshina, E.A., Bilinski, T., Plonka, A. \& Bartosz, G. (1995) Resistance to ionizing radiation and antioxidative defence in yeasts. Are antioxidant-deficient cells permanently stressed? Biochem. Mol. Biol. Int. 37, 467-473.

Jazwinski, S.M. (1990) Aging and senescence of the budding yeast Saccharomyces cerevisiae. Mol. Microbiol. 4, 337-343.

Jazwinski, S.M. (1996) Longevity, genes, and aging. Science 273, 54-59.

Kapahi, P., Boulton, M.E. \& Kirkwood, T.B. (1999) Positive correlation between mammalian life span and cellular resistance to stress. Free Radical Biol. Med. 26, 495-500.

Kennedy, B.K., Austriaco, N.R.J., Zhang, J. \& Guarente, L. (1995) Mutation in the silencing gene SIR4 can delay aging in S. cerevisiae. Cell 80, 485-496.

Kim, S., Kirchman, P.A., Benguria, A. \& Jazwinski, S.M. (1999) in Methods in Aging Research (Yu, B.P., ed.) 2nd edn., pp. 191-213, CRC Press, Boca Raton, Boston, London, New York, Washington.

Lee, J., Dawes, I.W. \& Roe, J.H. (1995) Adaptive response of Schizosaccharomyces pombe to hy- 
drogen peroxide and menadione. Microbiology 141, 3127-3132.

Lee, S.M. \& Park, J.W. (1998) Thermosensitive phenotype of yeast mutant lacking thioredoxin peroxidase. Arch. Biochem. Biophys. 359, 99-106.

Martinez-Pastor, M., Marchler, G., Schuller, C., Marchler, B.A., Ruis, H. \& Estruch, F. (1996) The Saccharomyces cerevisiae zinc finger proteins Msn2p and Msn4p are required for transcriptional induction through the stress response element (STRE). EMBO J. 15, 2227-2235.

Meaden, P.G., Arneborg, N., Guldfeldt, L.U., Siegumfeldt, H. \& Jakobsen, M. (1999) Endocytosis and vacuolar morphology in Saccharomyces cerevisiae are altered in response to ethanol stress or heat shock. Yeast 15, 12111222 .

Orr, W.C. \& Sohal, R.S. (1994) Extension of life-span by overexpression of superoxide dismutase and catalase in Drosophila melanogaster. Science 263, 1128-1130.

Seymour, I.J. \& Piper, P.W. (1999) Stress induction of HSP30, the plasma membrane heat shock protein gene of Saccharomyces cerevisiae, appears not to use known stress-regu- lated transcription factors. Microbiology 145, 231-239.

Shama, S., Kirchman, P.A., Jiang, J.C. \& Jazwinski, S.M. (1998a) Role of RAS2 in recovery from chronic stress: Effect on yeast life span. Exp. Cell Res. 245, 368-378.

Shama, S., Lai, C.Y., Antoniazzi, J.M., Jiang, J.C. \& Jazwinski, S.M. (1998b) Heat stress-induced life span extension in yeast. Exp. Cell Res. 245, 379-388.

VanLoon, A.P.G.M., Persold-Hurt, B. \& Schatz, G.A. (1986) A yeast mutant lacking mitochondrial manganese superoxide dismutase. Proc. Natl. Acad. Sci. U.S.A. 83, 3820-3824.

Wawryn, J., Krzepilko, A., Myszka, A. \& Biliński, T. (1999) Deficiency in superoxide dismutases shortens life span of yeast cells. Acta Biochim. Polon. 46, 249-253.

Wieser, R., Adam, G., Wagner, A., Schüller, Ch., Marchler, G., Ruis, H., Krawiec, Z. \& Bilinski, T. (1991) Heat shock factor-independent heat control of transcription of the CTT1 gene encoding the cytosolic catalase T of Saccharomyces cerevisiae. J. Biol. Chem. 266, 1240612411. 